\title{
Povos indígenas, saúde e ditadura Indigenous peoples, health and dictatorship
}

Jane Felipe Beltrão ${ }^{1}$

DOI:http://dx.doi.org/10.20435/tellus.v19i39.564

Resumo: Tomar a saúde como referência e analisar a História dos Povos Indígenas tendo por fonte os registros do Relatório Figueiredo é objetivo do artigo. Sabe-se que Jader de Figueiredo Correia não se preocupou com o tema saúde, entretanto os registros sobre as atrocidades cometidas, pelos funcionários do SPI, permitem verificar a precária assistência prestada, pela agência tutelar, às pessoas indígenas no período ditatorial, vivido no Brasil, na segunda metade do século XX. Mostrar a prática do genocídio praticado pela política indigenista que imbuída de "mentalidade empresarial" liberou às terras indígenas e produziu a dizimação de inúmeras etnias.

Palavras-chave: povos indígenas; saúde; ditadura; política indigenista.

Abstract: Taking health as a reference and analyzing the History of Indigenous Peoples from the records of the Figueiredo Report is the objective of the article. It is known that Jader de Figueiredo Correia did not care about the health issue, however the records on the atrocities committed by the SPI officials, allow to verify the precarious assistance provided by the tutelary agency to the indigenous people in the dictatorial period, lived in Brazil, in the second half of the 20th century. Show the practice of genocide practiced by the indigenist policy that imbued with "business mentality" liberated indigenous lands and produced the decimation of countless ethnic groups.

Keywords: indigenous peoples; health; dictatorship; indigenist policy.

\section{DO ANÚNCIO}

Durante quase meio século as atrocidades ocorridas em tempos ditatoriais ficaram "desaparecidas" entre as linhas do Relatório Figueiredo (RF) "abandonado", entre muitos outros documentos no Museu do Índio, no Rio de Janeiro. Os/as estudiosos/as sabiam da existência do documento, mas não conheciam o teor das investigações levadas a efeito, pela Comissão de Inquérito, presidida pelo

1 Universidade Federal do Pará (UFPA), Belém, Pará, Brasil. 
procurador Jáder de Figueiredo Correia, porque supostamente o documento teria ardido em incêndio ocorrido no Ministério da Agricultura.

O Relatório Figueiredo é um conjunto documental, constituído por 30 volumes, que é, talvez, o registro mais importante para pensar a relação do Estado brasileiro com os povos indígenas, especialmente, quando se toma etnicidade como política, a qual permite ver o genocídio, inscrito nas amareladas folhas do processo, apontando a opção do Estado brasileiro.

Foi encontrado, em 2012, pelo pesquisador Marcelo Zelic, vice-presidente do grupo Tortura Nunca Mais de São Paulo, que colocou ao alcance de estudiosos/as a partir do Armazém da Memória. Hoje, a documentação encontra-se no site do Museu do Índio e em outros locais da web interessados em conhecer a História.

O documento revela para os brasileiros as faces do indigenismo ou da política indigenismo, e altera radicalmente a História Indígena, pois se antes da "descoberta", os crimes cometidos contra os povos indígenas, não passavam de suspeita, agora, não faltam argumentos para indicar a crueldade das ocorrências, as quais abalam pessoas indígenas de diversas etnias, apenas pela leitura. Vi choro Palikur, Kadiuweu, Xakriabá e Tembé. Como informa Adonias Guiome Ioiô:

[...] quando li esse material pela primeira vez, em casa, como discente indígena do mestrado, para discutir em sala de aula foi completamente difícil e doloroso. Na verdade, já ouvia esse tipo de relato, "mas, não desse jeito". Então, durante a aula para a discussão e debate sobre esse texto, fiquei totalmente mudo, sem jeito, em silêncio, com raiva de sentir aquela dor enorme e profunda. (Depoimento em sala de aula, 2017).

O foco do artigo são as relações que indicam os atentados à saúde, os quais comprometeram a saúde e a vida de pessoas e coletivos indígenas que, deslocados forçosamente, sucumbiram ou amargaram a distância do território original em função da prática estatal.

\section{DOS REGISTROS}

Entre os registros encontrados no Relatório Figueiredo que, de alguma forma afetam a saúde dos povos indígenas, no período ditatorial, temos no Relatório Síntese (RS), produzido pelo procurador Jader de Figueiredo Correa, notas sobre o que ele qualifica como atrocidades de "[...] verdadeiros celerados, que lhes impu- 
seram um regime de escravidão [aos/as indígenas] e lhes negaram um mínimo de vida compatível com a dignidade da pessoa humana" (Fls. 4912). O que permite ao procurador afirmar que, mesmo não tendo a veleidade de conhecer o Serviço de Proteção aos Índios (SPI), "[o] pouco que me foi dado a ver é suficiente para causar espanto e horror" (Fls. 4911).

São denunciados/as funcionários/as do SPI que, nos diversos postos de serviço da Instituição, costumeiramente praticavam os seguintes delitos: espancamentos de homens, mulheres e crianças indígenas; envenenamento de coletivos indígenas colocando estricnina - substância tóxica usada como pesticida contra roedores - ao açúcar; inoculação de vírus da varíola em indígenas em Itabuna na Bahia; encarceramentos arbitrários, em prisões improvisadas, lembrando "[...] presídios de Luis XI, da França: uma escura caixa de madeira de cerca de 1,30 X 1,00 , construída dentro de um imundo pavilhão de pocilga e estrebaria" (RF Síntese: Fls. 4918); atendimento insatisfatório em enfermarias "[...] antro abjeto e sórdido, ocupado conjuntamente por cães, porcos e uma doente, no mesmo quarto infecto" (RF - Síntese: fls. 4918); incentivo à embriagues de indígenas, favorecendo o consumo de bebidas alcoólicas especialmente após maus tratos; escravidão de pessoas indígenas nos postos do SPI ou por intermédio de aluguel a terceiros; sonegação de medicamentos, mesmo quando estes existiam no posto; suplícios e torturas de diversas ordens, especialmente o "tronco", descrito como:

[...] o mais encontradiço de todos os castigos, imperando na $7^{\text {a }}$. Inspetoria. Consistia na trituração do tornozelo da vítima, colocando-o entre duas estacas enterradas juntas em ângulo agudo. As extremidades, ligadas por roldanas, eram aproximadas lenta e continuamente. (RF-Síntese: fls. 4913).

Há, ainda, registros referentes a: agressões físicas que resultam em quebra de ossos das pessoas indígenas; tentativas de assassinatos por enforcamento e mesmo registros de execução de pessoas que não obedeciam "cegamente" os funcionários do SPI, crimes que podiam ser executados pelos/as próprios/ as servidores/as ou via contratação de matadores; chacinas desferidas contra coletivos indígenas; não tratamento de tuberculosos/as, além do banimento dos mesmos, colocando-se "[...] um chocalho e andar com uma lata [para não contaminar os demais indígenas, especialmente da sua família], proibindo que se prestasse qualquer assistência [a ele], inclusive alimentação [...]" (RF - Síntese: fls. 4957), o fato levou o cidadão a morrer em completa inanição. Acredita-se que a 
lata referida no depoimento, tinha outra função: esmolar, entretanto pergunta-se: onde ele perambularia para recolher óbolos? O documento diz apenas que o referido doente era Bororo e morava na aldeia.

Muitas pessoas foram desterradas das terras de origem para territórios estranhos, em geral fazendas a título de castigo. Era a diáspora interna dos povos indígenas no Brasil, transplantados de um lugar a outro, pelo simples fato de serem indígenas. Fala-se de genocídio, não admitido, mas presente no território nacional, via a pesada mão do Estado. A diáspora indígena, como a africana era um verdadeiro tráfico humano e feito sob a batuta do Estado.

No caso, das indígenas mulheres os servidores e, mesmo as servidoras, "[...] [m]andavam as parturientes para os roçados um dia após o parto, deixando as criancinhas em uma Mansarda imunda sem terem direito de alimentaram os próprios filhos [...]" (RF - Síntese: fls. 4937).

Afora os crimes listados anteriormente, há no RF insistentes registros narrando: maus tratos de diferentes ordens; pessoas com fome; subnutridas e passado por situações que podem ser caracterizadas como omissão de atendimento; e evasão de divisas produzidas pelos/as próprios/as indígenas e desviadas para outros fins.

\section{DO CASO RELATIVO AO SERVIDOR FLÁVIO DE ABREU}

Fundamenta-se o caso em destaque, a partir do termo de inquirição de Juracy Cavalcante Ferreira, qualificada como brasileira, de prendas domésticas, esposa de José Baptista Ferreira Filho, ex-chefe da $6^{\text {a }}$ Inspetoria localizada no Mato Grosso; e do depoimento de Adalgiza de Tal que, sem sobrenome, é qualificada como índia Bororo, nascida e criada na aldeia. Ambos os termos referem-se às denúncias recebidas pela Comissão a respeito do servidor Flávio de Abreu, do Posto Indígena "Couto de Magalhães". O destaque conferido deve-se às atrocidades relatadas.

João Baptista Ferreira Filho, em face do inquérito, entregou ao procurador Jader de Figueiredo diversos relatórios referentes ao período em que esteve à

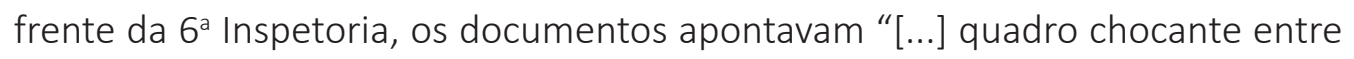
os Bororo de Mato Grosso." Cerca de 30 índios/as foram “[...] entregues por 
funcionários do SPI, não só a famílias de 'civilizados', mas também a prostíbulos" (VALENTE, 2017, p. 39).

É Ferreira Filho que, em 1964, informa que estava "arrecadando" [tentando recolher] pessoas indígenas que se encontravam em casa de particulares. Disse o servidor que encontrou uma índia Kajaby na casa de um desembargador do Tribunal de Justiça ${ }^{2}$. A continuidade da leitura da massa documental, permite afirmar que os casos se avolumavam, não se restringem ao Mato Grosso, avolumam-se por outros estados da Federação. Diz o denunciante que as pessoas - crianças, jovens e adultos - eram levadas (doadas, sequestradas, desterradas) - sem que se considerasse "os sentimentos humanos dessas criaturas", algumas delas "a título de castigo" (VALENTE, 2017, p. 39).

Muitas das pessoas eram retidas nas fazendas da região, alugadas que eram pelos/as servidores/as do SPI ou mesmo mantidas como propriedade de funcionários que se dedicaram a "roubar as terras indígenas" e apropriar-se das pessoas como se escravos fossem.

Aquelas pessoas ou coletivos indígenas que ousavam rebelar-se, por conta das atrocidades, eram punidas com severos espancamentos, muitas vezes aplicados pelos parentes próximos, práticas que se incluíam no rol das atrocidades de Flávio de Abreu. Caso o parente se recusasse, era também castigado, espancado ou supliciado (torturado). É o caso de Salú que se negou a espancar a própria mãe (RF vol. VIII: fls. 1682).

Entretanto o teatro de horrores não se encerra com as atrocidades citadas anteriormente. O que mais causa espécie nas práticas de Flávio de Abreu são as práticas de misoginia e abuso sexual de indígenas crianças, jovens e/ou adultas. "[...] as índias Adalgiza e Alice, de seis e sete anos de idade eram tidas como escravas de Flávio de Abreu, trabalhando para o mesmo no campo e em casa; que a índia Adalgisa era proibida de ver sua mãe, sendo espancadas toda vez que a guria fugia para visitar a mãe" (RF vol. VIII: fls. 1680-1681).

\footnotetext{
2 A prática parece corroborar as suspeitas relativas à entrega de crianças pelas autoridades judiciarias no estado do Pará. Nos anos sessenta era comum ouvir que a menina ou o menino tinham sido "deixados pelo juiz com tal ou qual família, para estudar, saídas ou aprisionadas em bordeis". Muitas crianças trabalhavam como empregadas/os domésticas/os, sem que ninguém se importasse procurar-lhes os pais.
} 
O caso da índia Rosa (etnia Bororo) é narrado no termo de inquirição de Juracy Ferreira informando que a menina (11 anos) foi recebida por Seabra, como pagamento pela confecção de um fogão de barro na fazenda Santa Terezinha de propriedade de Flávio de Abreu. A menina foi escolhida entre as estudantes que frequentavam a escola de Dona Violeta Tocantins. Flávio e Seabra entraram na escola e mandaram que as meninas ficassem de pé e imediatamente Seabra escolheu Rosa que the foi entregue imediatamente. Quando o pai de Rosa reclamou do acontecido, Abreu "[...] mandou surrar o reclamante [...] a surra foi aplicada pelos índios Otaviano Aiepa e Cojiba. Rosa só foi devolvida quando os trabalhos de Seabra foram concluídos (RF vol. VIII: fls. 1681).

Mais adiante, a inquirida revela que Flávio de Abreu criou um Serviço Médico que facilitava sua vida de "abusador", o serviço "[...] era destinado ao exame das índias de idade jovem", exames que eram realizados à noite. Quando interrogado sobre o serviço Abreu esclarecia que os exames constatavam a existência de moléstias venéreas (RF vol. VIII: fls. 1680).

Não bastassem as denúncias examinadas acima, as informações referentes ao abastecimento do "Couto de Magalhães" era precário, pois o administrador, rompeu a cadeia da organização social bororo no que diz respeito as redes de parentesco e obtenção alimentos tradicional entre os indígenas. As consequências foram imediatas, o que se produzia não permanecia no posto, assim sendo aos indígenas restava alimentar-se com "[...] grãos de milho seco e mamão verde cortado em pedaços [...]" e mesmo assim a precária comida era distribuída ao talante do administrador, pois tudo que era produzido pelos indígenas, inclusive grandes quantidades de farinha de mandioca, era vendido e, os produtores não auferiam renda alguma, tudo era embolsado pelo administrador (RF vol. VIII: fls. 1681).

É, também, Juracy Ferreira que nos informa com espanto que ao chegar em "Couto de Magalhães" constatou a inexistência de crianças indígenas, posteriormente tomou conhecimento que Abreu "[m]andava as parturientes para os roçados um dia após o parto, deixando as criancinhas em uma Mansarda imunda sem terem direito de alimentaram os próprios filhos" (RF vol. VIII: fls. 4937). O administrador obrigava as mulheres indígenas ao "[...] cumprimento de tarefas rurais impossibilitando as mesmas de cuidarem de seus filhos [...]" caso alguma das "[...] índias concluía a tarefa mais rapidamente para dêste modo prestar 
assistencia ao seu filho, no dia seguinte o Sr. Flávio de Abreu aumentava suas tarefas [...], enquanto duravam as tarefas das mães, os recém nascidos ficavam na casa da índia Maria Rosa, amázia de Flávio de Abreu [...] [sic]" (RF v. VIII: fls. 1680).

Sabe-se que nenhum dos 130 postos indígenas, distribuídos em 18 unidades da Federação, jamais tive em suas equipes enfermeiras/os ou médicos/as, portanto o clima de terror imposto no período ditatorial era suficiente para negar apoio àqueles que como tutelados/as deveriam ter os direitos preservados.

\section{DO CONTINUIDADE DAS AÇÕES POLÍTICAS}

Apesar de todas as atrocidades citadas, elas não ficaram encerradas, no passado próximo, como desejavam os homens de Estado. Convém lembrar as observações do Coronel Jarbas Gonçalves Passarinho, ao ser interrogado por jornalistas, sobre a prática de genocídio, respondeu "[é] verdade que existe esse problema, criado pela nossa própria imprensa, mas são coisas já ultrapassadas no tempo" (VALENTE, 2017, p. 46).

Se à época da declaração, em 1968, do líder arenista, que serviu aos governos militares, tentava encobrir a verdade, hoje temos a comprovação de que a mão pesada do Estado, ainda, responde presente e as atrocidades continuam a ser praticadas.

Trago à superfície o "tronco" tortura que "[...] era, todavia, o mais encontradiço de todos os castigos, imperando na $7^{a}$ Inspetoria. Consistia na trituração do tornozelo da vítima, colocado entre duas estacas enterradas juntas em ângulo agudo. As extremidades, ligadas por roldanas, eram aproximadas lenta e continuamente" (RF Síntese fls. 4913).

A prática aparece no RF como prática persecutória contra os povos indígenas, com registros nos postos de Ivaí, Nonoai e Guarita (RF Síntese, fls. 4911, 4926, 4937, 4943, 4952, 4965, 4965 e 4970). Em alguns postos, como Nonoai, além do suplício no "tronco" que triturava os tornozelos, quebravam o fêmur das vítimas caso de João Crespo. O suplício podia ser acompanhado pela aplicação da palmatória e também pela raspagem da cabeleira dos/as indígenas, afetando nesse caso a identidade étnica, pois os/as vitimados/as podiam ter, no corte de cabelo, um dos sinais da marca étnica. 
Ao falar sobre o assunto, em sala de aula, no Mato Grosso do Sul, analisando os casos acima, provoquei lágrimas em lideranças Kadiweu e Terena. E ouvi o depoimento de discente que trabalha em área Guarani: "[... não precisa ir longe, acontece aqui professora. Os policiais quando promovem a invasão de terras indígenas, por qualquer motivo, quebram os joelhos dos indígenas com coronhadas de revolver" (Depoimento em sala de aula, 2016).

Continuando, a inoculação hoje não é feita com o vírus da varíola. Nas retomadas Guarani, em Mato Grosso do Sul, se asperge em grandes quantidades pesticidas sobre os acampamentos, tal como se faz na lavoura, o avião passa muitas vezes sobre a cabeça das pessoas do coletivo indígena instalado no local, talvez, para ter certeza que atingiu o alvo humano de forma intensa.

O esbulho da terra, no momento, pode ser tomado como a implementação de grandes empreendimentos, que voltam a "desterrar" em deslocamentos forçados povos inteiros, na medida em que, sem consulta prévia e ignorando os efeitos sociais da proposta, se instala devastando os espaços de convivência cotidiana.

Manifesta-se também de forma pronunciada, quando o Estado procrastina as demarcações dos territórios indígenas, quando se nega a implantar escolas indígenas, ou a atender os povos indígenas que morando na cidade procuram atendimento em saúde.

Em tempos de golpe, no passado e no presente, o SPI ou a Fundação Nacional do Índio (FUNAI), como "braços" do Estado, teve seus dirigentes escolhidos, pelo agrado que faziam e fazem aos chefes políticos, sem que a pergunta essencial se faça ouvir: o que se sabe sobre povos indígenas, o que se faz para tratá-los com equidade?

Em última análise a política indigenista, no passado e no presente, foi/é racista; discriminava/discrimina; e, matava e continua a matar, além de atender os interesses da burguesia que se inspira em parâmetros brancos. É urgente, ouvir e agir, segundo a Política Indígena, determinada pelos movimentos indígenas, eles sabem o que os atormenta e a nós resta ser aliados/as solidários/as, pois nada parece ter mudado. 


\section{REFERÊNCIAS}

RELATÓRIO FIGUEIREDO: documento na íntegra. Boletim Combate Racismo Ambiental, 2013. "Síntese". Disponível em: http://racismoambiental.net.br/2013/06/02/relatoriofigueiredo-documento-naintegra-7-mil-paginas-pdf-pode-agora-ser-baixado/. Acesso em: 1o jul. 2017.

VALENTE, Rubens. Os fuzis e as flechas. A história de sangue e resistência indígenas na ditadura. São Paulo: Companhia de Letras, 2017.

\section{Sobre a autora:}

Jane Felipe Beltrão - Doutora em História pela Universidade Estadual de Campinas (UNICAMP). Mestre em Antropologia Social pela Universidade de Brasília (UnB). Docente titular exercendo atividades junto a Universidade Federal do Pará (UFPA) e lotada no Instituto de Filosofia e Ciências Humanas com atuação no Programas de Pós-Graduação em Antropologia e no Programa de Pós-Graduação em Direito. Bolsista Pq 1C/CNPq. E-mail: janebeltrao@gmail.com

Recebido em 30 de julho de 2018

Aprovado para publicação em 14 de novembro de 2018 
